\title{
Reduction of sperm transport in ewes by superovulation treatments
}

\author{
G. Evans* and D. T. Armstrong \\ M.R.C. Group in Reproductive Biology and Departments of Physiology and Obstetrics \& \\ Gynaecology, The University of Western Ontario, London, Ontario, Canada N6A 5 A5
}

\begin{abstract}
Summary. Oestrus was synchronized in ewes by (a) withdrawal of an intravaginal progestagen sponge after 12 days or (b) injection of PGF-2 $\alpha$ on Day 11 of the oestrous cycle. In addition, ewes were treated with (a) no hormone, (b) 1500 i.u. PMSG $48 \mathrm{~h}$ before sponge removal or PG injection, or (c) $24 \mathrm{mg}$ porcine pituitary FSH in multiple injections commencing $48 \mathrm{~h}$ before sponge removal or PG injection, in a $2 \times 3$ factorial design. Ewes were inseminated with $0.2 \mathrm{ml}$ fresh undiluted semen into the neck of the cervix $48 \mathrm{~h}$ after sponge removal or PG injection. Normally cyclic ewes were similarly inseminated within $12 \mathrm{~h}$ of observed standing oestrus.

At $24 \mathrm{~h}$ after insemination one uterine horn and one oviduct were flushed for recovery of spermatozoa and ova. When compared with naturally cyclic ewes, PG synchronization resulted in a marked reduction in the numbers of spermatozoa recovered $(P<0.05)$, and sponge synchronization led to a small, non-significant, reduction. Within the synchronized ewes, PMSG and FSH resulted in an equivalent superovulatory response, but there was a marked reduction in sperm recovery when compared with unstimulated animals $(P<0.01)$, with the greatest reduction attributable to PMSG treatment. Spermatozoa were recovered from fewer ewes treated with PMSG than with FSH $(P<0.05)$. Despite the observed impairment of sperm transport, a high fertilization rate was observed within each group and there were no differences between treatments.
\end{abstract}

\section{Introduction}

Failure of fertilization after superovulation is a major factor limiting the success of embryo transfer in sheep (Betteridge \& Moore, 1977; Armstrong \& Evans, 1983). That this impairment is the result of decreased sperm transport through the cervix associated with the superovulatory treatments has been inferred from observations that fertilization can be improved by the intrauterine deposition of spermatozoa by surgical means in superovulated ewes (Trounson \& Moore, 1974).

Superovulation treatment regimens normally consist of a follicle-stimulating hormone preparation such as pregnant mare serum gonadotrophin (PMSG) combined with either a synthetic progestagen administered via vaginal pessary or prostaglandin (PG) F-2 $\alpha$ (or a synthetic analogue) to control oestrus. Each of these, by itself, is known to affect fertilization adversely (Allison \& Robinson, 1970; Boland, Gordon \& Kelleher, 1978; Whyman \& Moore, 1980).

The decreased fertility resulting from progestagen and PG treatment in the absence of superovulation has been attributed to decreased transport of spermatozoa through the cervix, on the basis of direct measurements of the numbers of spermatozoa in various portions of the

* Present address: Department of Animal Husbandry, University of Sydney, Australia. 
reproductive tract (Quinlivan \& Robinson, 1969; Allison \& Robinson, 1970; Hawk \& Conley, 1975; Hawk \& Cooper, 1977). The present experiments were undertaken to compare the extent to which these oestrus-synchronizing agents, alone and in combination with two gonadotrophin preparations, PMSG and pituitary FSH, influenced numbers of spermatozoa in uteri and oviducts around the time of ovulation, as well as numbers attached to the zona pellucida of recovered oocytes. The extent to which intrauterine insemination increased numbers of spermatozoa at these sites in superovulated ewes was also examined.

\section{Materials and Methods}

Animals. Ewes and rams of predominantly Suffolk breeding were housed separately in open barns and were fed hay supplemented with grain according to normal local management practice. Ewes were purchased in Western Canada and allowed at least 4 weeks to acclimatize before the experiments. Most, but not all, ewes had lambed previously. They were randomly allocated to the treatment groups outlined below, and replicates within treatments were randomly distributed throughout the period of the experiment. At surgery, 3 ewes were discarded because of pyometra, and 1 ewe because of an infantile reproductive tract; these ewes were replaced to maintain a balanced design. Each ewe was used once only.

Treatments. Progestagen-impregnated vaginal sponges (Chronogest: Intervet, Angers, France) were inserted into 24 ewes at unknown stages of the oestrous cycle and removed after 12 days (Groups S). The ewes were inseminated $48 \mathrm{~h}$ after sponge removal. Another 24 ewes (Group PG) were given an i.m. injection of $150 \mu \mathrm{g}$ of the PGF- $2 \alpha$ analogue, cloprostenol (Estrumate: ICI Pharmaceuticals, Macclesfield, U.K.) on Day 11 of a cycle synchronized in the previous cycle with a progestagen sponge as outlined above and injection (i.m.) of 300 i.u. PMSG (Ayerst, Montreal, Canada) at the time of sponge removal. The ewes were inseminated $48 \mathrm{~h}$ after PG injection.

The 10 ewes in Group $C$ were used as 'natural' cycle controls. Oestrus in these ewes was synchronized in the previous cycle in the same way as the ewes in Group PG. On Day 15 of the subsequent cycle the ewes were exposed twice to intact rams and checked for overt signs of oestrus. Intromission was prevented by ventral sackcloth girdles on the rams. The time of first standing oestrus was taken as onset of oestrus. The ewes were artificially inseminated within $12 \mathrm{~h}$ of onset of oestrus.

The ewes in Groups $S$ and $P G$ were allocated equally to 3 subgroups and were treated with (i) no exogenous gonadotrophins, (ii) 1500 i.u. PMSG as a single i.m. injection in $3 \mathrm{ml}$ saline $(9 \mathrm{~g} \mathrm{NaCl} / \mathrm{l})$ $48 \mathrm{~h}$ before sponge removal of PG injection, and (iii) $24 \mathrm{mg}$ porcine pituitary FSH (FSH-P; BurnsBiotec Laboratories, Omaha, Nebraska, U.S.A.) given as a series of 8 twice-daily subcutaneous injections ( $3 \mathrm{mg}$ in $0.6 \mathrm{ml}$ saline per injection) starting $48 \mathrm{~h}$ before sponge removal or PG injection.

Semen collection and handling. Immediately before insemination, semen was collected by means of an artificial vagina into sterile plastic collecting vials and was held at $\sim 30^{\circ} \mathrm{C}$. It was checked for sperm motility and concentration according to the method of Salamon (1976). Only semen with wave motion $>4$ (scale $0-5)$ and sperm concentration $>3.2 \times 10^{9} / \mathrm{ml}$ was used. Semen from the 2 rams used in this experiment consistently met these criteria. When more than one ejaculate was required semen from each ram was pooled; otherwise the rams were randomly selected for use.

Insemination. The 58 ewes in Groups $\mathrm{S}, \mathrm{PG}$ and $\mathrm{C}$ were inseminated vaginally according to the method of Salamon (1976): $0.2 \mathrm{ml}$ fresh undiluted semen (containing $\sim 700 \times 10^{6}$ spermatozoa) was carefully deposited via a plastic disposable inseminating pipette into the neck of the cervix. Copious mucus in the vagina was drained before insemination. Eight additional ewes were treated with a progestagen sponge and FSH and surgically inseminated for comparison with vaginally inseminated ewes.

For surgical intrauterine insemination the ewes were fasted for $12 \mathrm{~h}$ and anaesthetized lightly with a $1: 1(\mathrm{v} / \mathrm{v})$ mixture of thiopentone sodium (50 mg Pentothal $/ \mathrm{ml}$ : Abbott Laboratories, Montreal, Canada) and pentobarbitone sodium (65 mg Somnotol/ml: MTC Pharmaceuticals, 
Hamilton, Canada). The semen was diluted with 2 volumes of Dulbecco's phosphate-buffered saline (PBS) and held at $30^{\circ} \mathrm{C}$. The insemination volume was $0.1 \mathrm{ml}$ (containing $\simeq 115 \times 10^{6}$ spermatozoa).

For insemination, ewes were suspended upside-down at an angle of $60-70^{\circ}$ from the horizontal on a laparotomy cradle. The abdominal cavity was inflated with $\mathrm{CO}_{2}$, and the semen was injected by means of a sharp inseminating pipette into the lumen of one uterine horn at a convenient point, under direct laparoscopic visualization (Armstrong \& Evans, 1984).

Sperm recovery. All ewes were subjected to mid-ventral laparotomy $22-26 \mathrm{~h}$ after insemination. This time was chosen since maximum numbers of spermatozoa have been recovered from the oviducts of ewes in natural oestrus (Mattner, 1963) or progestagen sponge-synchronized oestrus (Quinlivan \& Robinson, 1969) $24 \mathrm{~h}$ after coitus or insemination. The ewes were fasted for $12 \mathrm{~h}$ and anaesthesia induced with thiopentone sodium and maintained with halothane (Somnothane: Hoechst Pharmaceuticals, Montreal, Canada). The uterus and ovaries were exposed and ovulation points and large Graafian follicles recorded. One uterine horn and oviduct was flushed with PBS for recovery of spermatozoa and ova; the horn to be flushed was chosen randomly except when there was a unilateral ovulation, in which case the horn adjacent to the ovary with the ovulation point(s) was selected. The oviduct was flushed with $2.5 \mathrm{ml}$ PBS through a stab wound just below the tubo-uterine junction, and the flushings collected in a small Petri dish by means of a polyurethane catheter inserted in the fimbria and gripped between the thumb and forefinger. The uterine horn was flushed with $10 \mathrm{ml}$ PBS through the same stab wound, and the flushings collected through a Foley catheter inserted into the uterine lumen close to the bifurcation. The uterus was massaged gently to mix and express the flushing through the Foley catheter for collection in a plastic vial.

In some ewes exhibiting bilateral ovulation at the time of uterine flushing to recover spermatozoa, the other horn was flushed 2-3 days later for collection of embryos as described by Armstrong, Pfitzner, Warnes \& Seamark (1983).

The flushings were examined immediately under a dissecting microscope and any ova/embryos were collected using a drawn-out Pasteur pipette, transferred to a Petri dish containing fresh PBS and examined under an inverted microscope. Numbers of ova with spermatozoa attached to the zona pellucida and numbers exhibiting cell division consistent with embryonic development were recorded. A drop of the flushing was transferred to a microscope slide on a warm stage and, when sufficient numbers were available, an assessment of sperm motility was made. The remainder of each flushing was stored in a plastic vial at $4^{\circ} \mathrm{C}$ for $1-3$ days until sperm numbers were counted.

Sperm counts. Spermatozoa were counted in flushings of uterine horns and oviducts separately, using a Nikon SC light microscope with the $\times 20$ objective lens. Four spots of Vaseline were placed at the corners of a $17 \mathrm{~mm}$ square on a microscope slide. In the centre of these spots $30 \mu \mathrm{l}$ of wellmixed flushing were placed, an $18 \mathrm{~mm}$ coverslip was placed on top, and uniformly compressed until the fluid reached all four edges of the coverslip. Six edge to edge sweeps, each of $0.45 \mathrm{~mm}$, were made of each preparation and spermatozoa were counted. This procedure was repeated once for each flushing sample. When the total number of sperm counts was $>50$ no further counts were made; otherwise, the flushing was centrifuged at $200 \mathrm{~g}$ for $10-15 \mathrm{~min}$, the supernatant was decanted and the sperm pellet was resuspended in $0.5 \mathrm{ml}$ saline. The counting procedure was repeated. Total sperm numbers recovered from each site were calculated by multiplying sperm concentration in the aliquot of flushing medium examined by the total volume of PBS used to flush each site. Results are expressed as total sperm numbers recovered from one horn of the uterus and one oviduct. Since preliminary analysis of the data separately appeared to provide no extra information, counts for uterus and oviducts have been combined into a single figure.

Statistical analyses. When appropriate, standard $\chi^{2}$ and analysis of variance procedures were used. The heterogeneity of variance of the sperm count data, as detected by Bartlett's test, was successfully eliminated by use of a $\log _{10}(x+1)$ transformation. Specific comparisons were made using Duncan's Multiple Range Test, with significance, in most instances, being taken at the level of $P<0.05$. 


\section{Results}

\section{Ovulation rate}

The numbers of ewes which had ovulated by the time of the first laparotomy $24 \mathrm{~h}$ after vaginal insemination was significantly increased by treatment with exogenous gonadotrophin $(P<0.01)$ (Table 1). Since some ewes which received no exogenous gonadotrophin had not ovulated by the time of the first laparotomy, presumptive ovulation rate was estimated in these individuals by counting the number of follicles that appeared to be preovulatory on the basis of size and hyperaemic appearance. Taken overall (Table 1), the gonadotrophin treatments (FSH and PMSG) markedly stimulated ovulation rates over those of controls $(P<0 \cdot 01)$, but did not appear to differ from each other in ability to cause superovulation under the conditions used.

\section{Sperm recovery}

No spermatozoa were found in flushings from several animals. Therefore the data were analysed in two ways: qualitatively, i.e. on an all-or-none basis, according to whether or not any spermatozoa were found; and quantitatively, whereby the mean numbers of spermatozoa recovered were compared (Table 1 ).

The results of the qualitative analysis, excluding the Group $\mathrm{C}$ (natural cycle) ewes, indicated a significant $(P<0.05)$ effect of treatment on incidence of sperm recovery (no. of ewes in which spermatozoa were found/total no. of ewes examined). Partitioning the $\chi^{2}$ revealed no effect of gonadotrophin within the Group PG ewes, but an effect of gonadotrophin $(P<0.05)$ within the Group $S$ ewes. Considering only the gonadotrophin-treated ewes over both synchronization methods, a significantly higher $(P<0.05)$ incidence of sperm recovery was observed in FSHtreated than in PMSG-treated ewes. The tendency toward a lower incidence of sperm recovery in Group PG than in Group $S$ over all gonadotrophin treatments was not significant $(P=0 \cdot 08)$. Comparing the three groups (C, S and $\mathrm{PG}$ ) that received no gonadotrophin, the reduction observed in the PG group was statistically significant $(P<0.05)$.

Table 1. Ovulation rates, sperm recovery from uterine horns and oviducts, and presumptive fertilization in ewes as influenced by various superovulation regimens

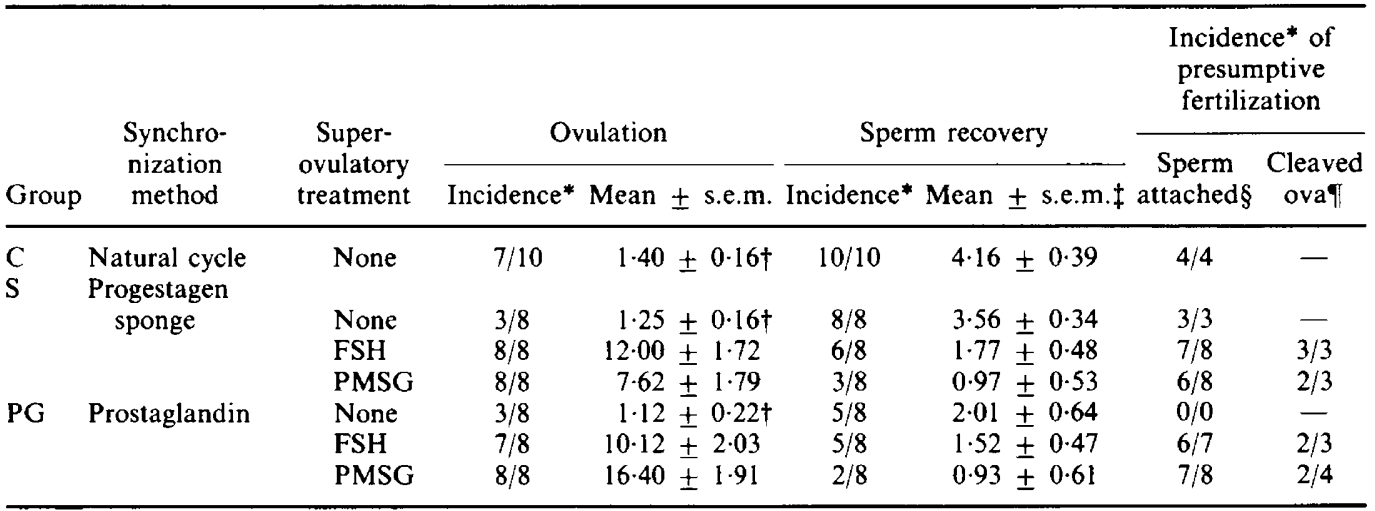

* No. of ewes exhibiting event/total no. of ewes observed, for each variable.

† Includes presumptive ovulations, based on preovulatory appearance of follicles in ewes that had not ovulated at the time of first laparotomy $24 \mathrm{~h}$ after insemination.

$\ddagger$ Expressed as $\log _{10}(x+1)$, where $x=$ total number of spermatozoa recovered in one uterine horn and oviduct, flushed $24 \mathrm{~h}$ after insemination.

$\S$ No. of ewes yielding ova with spermatozoa attached to the zona pellucida/total no. of ewes from which ova were recovered from oviducts flushed $24 \mathrm{~h}$ after insemination.

T No. of ewes yielding cleaved ova (embryos)/total no. of ewes from which ova or embryos were recovered from oviducts and uteri flushed 3-4 days after insemination. 
The results of the quantitative analysis of the transformed sperm count data, excluding the Group $C$ ewes, indicated a significant $(P<0.01)$ effect of exogenous gonadotrophin treatment (Table 1). Sperm numbers were significantly reduced in both gonadotrophin-treated groups below those found in ewes which received no gonadotrophin, but no significant difference was detected between FSH- and PMSG-treated ewes. The overall difference between numbers of spermatozoa recovered from Groups $S$ and $P G$ was not significant $(P=0 \cdot 16)$. Considering only the three groups which received no gonadotrophin, sperm numbers observed in the PG group were significantly lower than those in the $\mathrm{C}$ and $\mathrm{S}$ groups $(P<0.05)$.

Flushings from a limited number of ewes were examined immediately after recovery, enabling estimates to be made of motility of the recovered spermatozoa. These estimates were generally in the $30-60 \%$ range, although the number of observations was too low to permit meaningful comparisons between treatment groups, or between the uterine horns and oviducts.

\section{Fertilization}

At laparotomy $24 \mathrm{~h}$ after insemination, almost all ova were still at the single-cell stage, although 2-cell embryos were occasionally observed. A high proportion of ova recovered from most ewes had one or more spermatozoa attached to the zona pellucida at this stage (Table 1). Similarly, embryos that had reached at least the 8-cell stage were found in the uterine flushings of most ewes when the opposite horns were flushed 2-3 days later (Table 1). It therefore seems likely that the presence of spermatozoa attached to ova recovered at $24 \mathrm{~h}$ was indicative of incipient fertilization, if it had not already occurred. There were no significant differences attributable to treatments, in the proportion of ewes yielding ova with spermatozoa attached, or cleaved ova.

\section{Insemination method}

Only FSH-treated ewes in Group $\mathrm{S}$ were used in this experiment. Ovulation rates, sperm recovery and fertilization data are summarized in Table 2. Although approximately 6 times as many spermatozoa were deposited in the cervical os as in the intrauterine site, the mean intrauterine sperm population was 100 -fold greater in ewes inseminated surgically than in those inseminated vaginally $(P<0.05)$. Despite this large difference, there was no significant difference between the two treatments in the incidence of presumptive fertilization, based on the presence of spermatozoa attached to the zona pellucida of ova recovered 1 day after insemination. However, considerably larger numbers of spermatozoa were attached to ova recovered on Day 1 from surgically inseminated than from vaginally inseminated ewes (data not shown).

Table 2. Ovulation rates, sperm recovery from uterine horns and oviducts, and presumptive fertilization in ewes inseminated by cervical $\left(700 \times 10^{6}\right.$ spermatozoa deposited in external os of cervix in $0.2 \mathrm{ml}$ undiluted semen $)$ and intrauterine $\left(115 \times 10^{6}\right.$ spermatozoa, diluted in PBS, injected into lumen of uterus at laparoscopy) routes*

\begin{tabular}{ccccccc}
\hline \multirow{2}{*}{$\begin{array}{c}\text { Insemination } \\
\text { site }\end{array}$} & \multicolumn{2}{c}{ Ovulation } & & \multicolumn{2}{c}{ Sperm recovery } & $\begin{array}{c}\text { Incidence of } \\
\text { presumptive } \\
\text { fertilization }\end{array}$ \\
\cline { 2 - 3 } & Incidence & Mean \pm s.e.m. & & Incidence & Mean \pm s.e.m. & \\
\hline Cervix & $8 / 8$ & $12.00 \pm 1.72$ & & $6 / 8$ & $1.77 \pm 0.48$ & $7 / 8$ \\
Uterus & $7 / 8$ & $10.25 \pm 2.01$ & & $7 / 8 \dagger$ & $3.60 \pm 0.56$ & $6 / 7 \dagger$ \\
\hline
\end{tabular}

* See footnotes to Table 1 for definitionshatid ajts.

$\dagger$ Includes data from one ewe showit semen was injected into uterine stroma. 


\section{Discussion}

It is apparent from these experiments that interference with the natural oestrous cycle of the ewe by exogenous hormone treatment, whether for purposes of synchronization of oestrus or for superovulation, results in an impairment of sperm transport to the uterus and oviducts when ewes are artificially inseminated by the vaginal route. With regard to the method of synchronization of oestrus in the absence of gonadotrophin, the reduction in sperm numbers in the uterus and oviducts was most pronounced in prostaglandin-synchronized ewes, in essential agreement with previous reports (Hawk \& Conley, 1975; Hawk \& Cooper, 1977). The less-pronounced reduction in numbers in ewes synchronized with progestagen sponges was not significant, although other workers using larger numbers of animals have demonstrated an impairment of sperm transport due to this treatment (Quinlivan \& Robinson, 1969; Allison \& Robinson, 1970; Hawk \& Conley, 1975).

In comparison with unstimulated ewes, there was a significant reduction in incidence of sperm recovery and sperm numbers recovered in the uterus and oviducts after superovulation by both FSH and PMSG. The incidence of sperm recovery was lower in PMSG- than in FSH-treated ewes, perhaps related to the different abilities of the two gonadotrophin preparations to stimulate oestradiol secretion even though the degree of superovulation by the two treatments did not differ significantly. Although we have no data on oestradiol levels produced as a result of the two gonadotrophin preparations in the present study, in goats treated with similar gonadotrophin regimens peri-ovulatory blood oestradiol levels were more elevated and for a longer period after superovulation with PMSG than with FSH (Armstrong, Pfitzner, Warnes, Ralph \& Seamark, 1983). Hawk \& Conley (1975) have shown that exogenous oestrogen administered at the time of oestrus to intact ewes adversely affects sperm transport.

Despite the large differences in sperm numbers recovered from the uterus and oviducts due to the synchronization and superovulation treatments, there appeared to be no impairment of fertility as judged by the presence of spermatozoa on the zona pellucida of recovered ova, or by embryo recovery 2-3 days later. This suggests that the number of spermatozoa used in these inseminations exceeded greatly the minimum number required for maximum fertilization. Minimum numbers needed for normal conception rates in naturally cyclic ewes have been estimated previously at 120 $\times 10^{6}$ for AI (Allison \& Robinson, 1971) and $60 \times 10^{6}$ for natural mating (Fulkerson, Synnott \& Lindsay, 1982), or approximately $1 / 5$ and $1 / 10$, respectively, of the number used in the present experiment.

In several ewes in the present study, spermatozoa were found on ova but not in the remainder of the uterine or oviducal flushings; in these instances we must assume that other spermatozoa had found their way to the oviduct but had passed through to the peritoneal cavity or had been phagocytosed before flushing. Nevertheless, it is an illustration that fertilization can occur when sperm numbers in the reproductive tract are extremely limited. In those ewes in which the second uterine horn was flushed 2-3 days after the first, viable embryos were recovered from all except 1 ewe which had yielded ova with spermatozoa attached at the earlier flushing. In this exceptional ewe, luteal failure was evident at the time of the second laparotomy; therefore, the failure to obtain embryos in this animal cannot be attributed to fertilization failure. It therefore appears that the presence of spermatozoa attached to the zona pellucida is correlated with fertilization. The relationship between numbers of spermatozoa attached to the zona pellucida and the presence or absence of fertilization reported by Hunter, Barwise \& King (1982) supports this interpretation.

We have previously observed that naturally mated superovulated ewes with more than 16 ovulations exhibited a marked reduction in fertility when compared with those ewes with fewer ovulations (Armstrong \& Evans, 1983). In the present experiments, of the 5 ewes in which all recovered ova lacked attached spermatozoa, 3 had $>16$ ovulations and one had a similar number of large cystic follicles. It therefore appears that the failure of fertilization in superovulated ewes is related more to the ovulatory response than to the exogenous gonadotrophin per se (see also Betteridge \& Moore, 1977). 
Trounson \& Moore (1974) demonstrated an improvement in fertilization in superovulated ewes by the use of surgical insemination. The greater number of spermatozoa in the uterus and oviducts around the time of ovulation and fertilization observed in the present ewes, inseminated with a technique which by-passes the cervix, supports the interpretation of Trounson \& Moore (1974) that poor fertilization rates in superovulated ewes may be due to inefficient sperm transport through the cervix. These findings provide a probable explanation for the improved fertilization reported for superovulated ewes inseminated into the uterus with frozen semen or with greatly reduced numbers of spermatozoa (Armstrong \& Evans, 1984). The relative ease with which intrauterine insemination may be accomplished with the aid of a laparoscope (Killeen \& Caffery, 1982; Armstrong \& Evans, 1984) may place this technique within the practical realm, at least when the aim is to maximize fertilization, as for the purpose of embryo transfer.

We thank Mr G. Young for animal care and technical assistance; Dr M. Harding, Dr R. Chibber and Mr G. Barbe for surgical assistance; and Ms. A. Rouleau-Coulter and Ms N. Colvin for assistance with laboratory procedures.

This research was supported, in part, by grants from the Medical Research Council of Canada, and Agriculture Canada. D.T.A. is a Career Investigator of the Medical Research Council of Canada.

\section{References}

Allison, A.J. \& Robinson, T.J. (1970) The effect of dose level of intravaginal progestagen on sperm transport, fertilization and lambing in the cyclic Merino ewe. $J$. Reprod. Fert. 22, 515-531.

Allison, A.J. \& Robinson, T.J. (1971) Fertility of progestagen-treated ewes in relation to the numbers and concentration of spermatozoa in the inseminate. Aust. J. biol. Sci. 24, 1001-1008.

Armstrong, D.T. \& Evans, G. (1983) Factors influencing success of embryo transfer in sheep and goats. Theriogenology 19, 31-42.

Armstrong, D.T. \& Evans, G. (1984) Intrauterine insemination enhances fertility of frozen semen in superovulated ewes. J. Reprod. Fert. (in press).

Armstrong, D.T., Pfitzner, A.P., Warnes, G.M., Ralph, M.M. \& Seamark, R.F. (1983) Endocrine responses of goats after induction of superovulation with PMSG and FSH. J. Reprod. Fert. 67, 395 401.

Armstrong, D.T., Pfitzner, A.P., Warnes, G.M. \& Seamark, R. F. (1983) Superovulation treatments and embryo transfer in Angora goats. J. Reprod. Fert. 67, 403-410.

Betteridge, K.J. \& Moore, N.W. (1977) Techniques and results in sheep and goats. Superovulation. In Embryo Transfer in Farm Animals. A Review of Techniques and Applications, pp. 37-38. Can. Dept. Agric., Monograph 16, Ottawa.

Boland, M.P., Gordon, I. \& Kelleher, D.L. (1978) The effect of treatment by prostaglandin analogue (I.C.I.$80,996)$ or progestagen (SC-9880) on ovulation and fertilization in cyclic ewes. J. agric. Sci., Camb. 91, $727-730$.

Fulkerson, W.J., Synnott, A.L. \& Lindsay, D.R. (1982)
Numbers of spermatozoa required to effect a normal rate of conception in naturally mated Merino ewes. $J$. Reprod. Fert. 66, 129-132.

Hawk, H.W. \& Conley, H.H. (1975) Involvement of the cervix in sperm transport failures in the reproductive tract of the ewe. Biol. Reprod. 13, 322-328.

Hawk, H.W. \& Cooper, B.S. (1977) Sperm transport into the cervix of the ewe after regulation of estrus with prostaglandin or progestagen. J. Anim. Sci. 44, 638644.

Hunter, R.H.F., Barwise, L. \& King, R. (1982) Sperm transport, storage and release in the sheep oviduct in relation to the time of ovulation. Br. vet. $J .138,225-$ 232.

Killeen, I.D. \& Caffery, G.J. (1982) Uterine insemination of ewes with the aid of a laparoscope. Aust. vet. J. 59, 95.

Mattner, P.E. (1963) Spermatozoa in the genital tract of the ewe. II. Distribution after coitus. Aust. J. biol. Sci. 16, 688-694.

Quinlivan, T.D. \& Robinson, T.J. (1969) Numbers of spermatozoa in the genital tract after artificial insemination of progestagen-treated ewes. J. Reprod. Fert. 19, 73-86.

Salamon, S. (1976) Artificial Insemination of Sheep. Dept. Anim. Hus., Monograph, University of Sydney.

Trounson, A.O. \& Moore, N.W. (1974) Fertilization in the ewe following multiple ovulation and uterine insemination. Aust. J. biol. Sci. 27, 301-304.

Whyman, D. \& Moore, R.W. (1980) Effects of PMSG and the prostaglandin F-2 $\alpha$ analogue, cloprostenol, on superovulation, fertilization and egg transport in the ewe. J. Reprod. Fert. 60, 267-272. 